\title{
Efficacy of Pomegranate Seed Powder on Glucose and Lipid Metabolism in Patients with Type 2 Diabetes: A Prospective Randomized Double-Blind Placebo-Controlled Clinical Trial
}

\author{
Monire Seyed Hashemi $^{a}$ Nasim Namiranian ${ }^{b}$ Hemaseh Tavahen ${ }^{a}$ \\ Abolfazl Dehghanpour ${ }^{\mathrm{a}}$ Mohammad Hadi Rad ${ }^{\mathrm{c}}$ Saeedeh Jam-Ashkezari ${ }^{\mathrm{b}}$ \\ Majid Emtiazy ${ }^{a, d}$ Mohammad Hashem Hashempure, $f$ \\ a Department of Persian Medicine, The School of Persian Medicine, Shahid Sadoughi University of Medical \\ Sciences, Yazd, Iran; b Yazd Diabetes Research Center, Shahid Sadoughi University of Medical Sciences, Yazd, Iran; \\ ${ }^{c}$ Agricultural and Natural Resource Research and Education Center, Agriculture Research Education and Extension

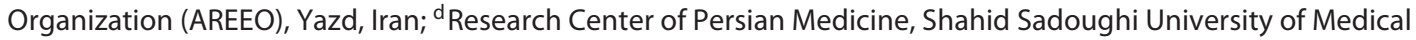 \\ Sciences, Yazd, Iran; ${ }^{e}$ Noncommunicable Diseases Research Center, Fasa University of Medical Sciences, Fasa, Iran;

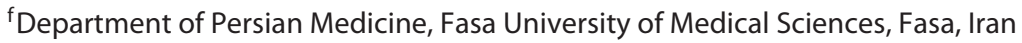

\section{Keywords \\ Type 2 diabetes mellitus · Pomegranate seed · Punica granatum · Glycemic indices · Triglyceride $\cdot$ Cholesterol · Traditional Persian medicine $\cdot$ Complementary medicine}

\begin{abstract}
Introduction: Pomegranate is known as a functional food which has multiple health-promoting activities. It has been assessed for patients with metabolic syndrome. Specifically, an antidiabetic activity of its juice and plausible mechanisms for its action have been shown in multitudinous studies. The aim of this study was assessing the effects of complementary treatment with pomegranate seed powder (PSP) oral supplementation on patients with type 2 diabetes mellitus (T2DM). Methods: Sixty patients were treated for 8 weeks by $5 \mathrm{~g}$ PSP or placebo, twice daily. Fasting blood glucose (FBG), glycated hemoglobin $\left(\mathrm{HbA}_{1 \mathrm{c}}\right)$, total cholesterol, and triglyceride (TG) were recorded as the outcome measures at the beginning and after the intervention. The findings were analyzed using the independent $t$ test and Mann-Whitney $U$ test. Results: After 8 weeks, the mean differences of FBG, $\mathrm{HbA}_{1 c}$, cholesterol, and TG were significantly decreased in the PSP group when compared with the placebo group ( $p$ value $<0.05$ ). In addition, post-intervention values of FBG
\end{abstract}




\section{Zusammenfassung}

Einleitung: Der Granatapfel ist als funktionelles Lebens mittel bekannt, das viele gesundheitsfördernde Wirkungen ausübt. Sein Nutzen für Patienten mit metabolischem Syndrom ist bereits untersucht worden. Konkret wurden die antidiabetische Wirkung des Safts sowie plausible Wirkmechanismen in zahlreichen Studien betrachtet. Das Ziel dieser Studie war die Beurteilung der Effekte einer komplementären Behandlung mit Pulver aus Granatapfelkernen (GKP) als oraler Nahrungsergänzung bei Patienten mit Diabetes mellitus Typ 2 (Typ-2-Diabetes). Methoden: 60 Patienten wurden 8 Wochen lang mit 5 g GKP oder Plazebo zweimal täglich behandelt. Nüchternblutzucker (NBZ), Glykohämoglobin $\left(\mathrm{HbA}_{1 \mathrm{c}}\right)$, Gesamtcholesterin und Triglyzerid (TG) wurden als Messgrößen zu Beginn und nach Ende der Intervention erfasst. Die Auswertung der Ergebnisse erfolgte mittels unabhängigem $t$-Test und Mann-Whitney-U-Test. Ergebnisse: Nach 8 Wochen zeigten die mittleren Differenzen bei NBZ, $\mathrm{HbA}_{1 \mathrm{c}}$ Cholesterin und TG in der GKP-Gruppe einen signifikant stärkeren Rückgang als in der Plazebogruppe ( $p$-Werte $<0,05)$. Auch die NBZ- und $\mathrm{HBA}_{1 \mathrm{c}}-$ Werte nach der Studienbehandlung waren in der GKP-Gruppe signifikant niedriger als in der Plazebogruppe ( $p$-Werte $=0,02$ bzw. $0,01)$. Bei Cholesterin und TG hingegen bestand in letzterer Hinsicht kein signifikanter Unterschied ( $p$-Werte $=$ 0,51 bzw. 0,26). Schlussfolgerung: Die komplementäre Behandlung mit GKP scheint sich günstig auf den NBZ und $\mathrm{HbA}_{1 \mathrm{c}}$ von Patienten mit Typ-2-Diabetes auszuwirken. Die Auswirkung auf TG und Cholesterin hingegen war nicht eindeutig.

๑) 2020 S. Karger AG, Basel

\section{Introduction}

Diabetes mellitus (DM) is a metabolic disorder mainly characterized by chronic hyperglycemia. There is a pathological change in secretion, action, or both secretion and action of insulin which disturbs the metabolism of carbohydrate, fat, and protein [1]. Nowadays, scientists are considering DM as an inflammatory condition, too. It seems that chronic inflammation can be a potent predisposing factor for the development of type 2 diabetes mellitus (T2DM). In addition, it has been shown that subclinical inflammation can result in insulin resistance and metabolic syndrome. Oxidative stress is believed to be another important pathway in the development of T2DM. Oxidative stress resulting from hyperglycemia increases pro-inflammatory proteins and inflammatory cytokines [2,3].

According to the International Diabetes Federation's report, over 463 million adults had DM in 2019 worldwide. Additionally, if the current trend continues up to
2,045, patients with DM will reach 700 million [4]. It should be noted that the highest growing trend is for the Middle East and North Africa regions until 2040 (from 35.4 million in 2015 to 72.1 million in 2040) [5]. DM puts a heavy burden on humankind. In 2015, the Global Burden of Diseases, Injuries, and Risk Factors Study reported an increasing burden of high fasting glucose level: from the tenth in 1990 to fourth and then third most common global risk factors for disability-adjusted lifeyears in 2005 and 2015, respectively [6]. Additionally, $>90 \%$ of patients with DM have T2DM [7].

Lifestyle modification and social support are the 2 cornerstones in the management of T2DM [8]. Moreover, there are several generations of medications which are considered as a main driver for its management. However, the outcomes are not too satisfactory "in the face of evidence" [9].

Nowadays, there is a growing demand for different complementary and alternative medicine methods. Furthermore, patients with chronic diseases, like DM, are at a higher possibility for complementary and alternative medicine use [10-14]. It seems that medicinal plants are the most referred ones amongst other complementary and alternative medicine options $[15,16]$.

Pomegranate or Anār in Persian (Punica granatum L.) is a well-known fruit which belongs to the Lythraceae family and has a worldwide distribution $[17,18]$. Different parts of the plant, such as fruits (including its juice and peel), flowers, leaves, and roots were traditionally used to prevent and treat a wide variety of diseases $[19,20]$. Nowadays, it is known as a functional food which has multiple health-promoting activities [21]. For example, it is a potent anti-inflammatory and antioxidant [22-24], anticancer [25], vasculoprotective [26], and antihypertensive [20,27] herb. Additionally, it has been used for patients with metabolic syndrome [28]. Specifically, the antidiabetic activity of pomegranate's different parts and plausible mechanisms for its action have been shown in multitudinous studies $[18,19,29-$ 31]. Pomegranate phytochemicals (e.g., polyphenols, gallic, oleanolic, and ursolic acids, punicalagin, and ellagic acid) can efficiently reduce oxidative stress, lipid peroxidation, and inflammation. They can neutralize the generated reactive oxygen species. Also, some of the antioxidant enzyme activities (such as metal chelation, nuclear factor $\mathrm{\kappa B}$ and peroxisome proliferator-activated receptor $\gamma$ modification) are thought to be increased by them [32].

Despite the aforementioned data, there are scarce clinical studies on pomegranate seed powder's (PSP) effects on patients with T2DM. Therefore, this randomized controlled clinical trial was designed to assess the effects of PSP on glycemic and lipid outcomes in these patients. 


\section{Materials and Methods}

\section{Study Design}

This study is a prospective double-blind randomized placebocontrolled clinical trial. Participants were allocated to 2 parallel arms of the study with an allocation ratio of 1:1. It should be noted that there were no changes in the design and methods of the study after the commencement of the trial.

\section{Preparation of the Test and Control Tea Bags}

Pomegranate seeds were separated from arils and then dried in laboratory conditions for 15 days. The dried seeds were later milled using a mechanical grinder. Also, high-molecular weight polyethylene glycol (HWPEG) was used for the control group. They were packaged as tea bags containing $5 \mathrm{~g}$ of PSP or HWPEG for the test and control groups, respectively. PSP and HWPEG tea bags were packaged in the same containers. Additionally, their color and odor were similar.

\section{Participants}

The studied population consisted of patients with T2DM (based on American Diabetes Association Guidelines, 2016 [33]) who were referred to the Diabetes Research Center of Yazd, Yazd province in central Iran, from April to September 2017. Patients aged 30-60 years were included if their DM duration was between 1 and 10 years, and were on oral hypoglycemic agents (not insulin). Exclusion criteria were cardiovascular diseases, diabetic nephropathy or retinopathy, thyroid dysfunction, body mass index $>35$, smoking, breastfeeding, and pregnancy. Also, patients were excluded due to the use of vitamin supplements and $\omega-3$ within 3 weeks before the research. Patients who were vegetarian were excluded, too.

Randomization, Allocation Concealment, and Blinding

Patients' recruitment was based on simple sampling. The enrolled patients were assigned to the study arms by the secretary of the center, using a randomization list. The list was generated by a biostatistician, using Epi Info $^{\mathrm{TM}}$ software. Also, allocation concealment was done using sequentially numbered opaque pockets. The pockets contained letters A (treatment group) or B (control group).

Both of the prescribed medicines were packaged in the same containers labeled by A or B. The physicians and patients were not informed about the containers' content. Also, the researchers could decode the contents of each container only in emergency situations. It should be noted that the packages were given by a third person (not involved in the study team) to patients.

\section{Intervention}

Patients in both groups were advised not to change their conventional medicines (including lipid and glucose-lowering agents). The intervention group (including 12 females and 21 males) received complementary treatment (i.e., beside oral hypoglycemic agents as conventional treatment for T2DM) of $5 \mathrm{~g}$ of PSP twice a day (in the morning on an empty stomach, then at night before bedtime) for a period of 8 weeks. PSP was delivered to patients as herbal tea bag which should be placed in hot water for $10 \mathrm{~min}$. They were advised not to boil the tea bags and just put them in the boiled (hot) water. Patients in the control group (including 19 females and 13 males) were advised similarly. However, the tea bags which were delivered to them contained $5 \mathrm{~g}$ of HWPEG.

It should be noted that both groups were advised not to take any supplement and not to change their dietary and lifestyle habits during the intervention period. Moreover, patients' adherence to the trial's protocol was assessed by telephone survey.

\section{Outcome Measures}

Biochemical outcomes including fasting blood glucose (FBG), glycated hemoglobin $\left(\mathrm{HbA}_{1 \mathrm{c}}\right.$; both of them as the primary outcome measures), total cholesterol, and triglyceride (TG; as the secondary outcome measures) were measured at the enrollment point (i.e., baseline) and after completing the 8-week period of intervention. Patients were advised to be fasting for $12 \mathrm{~h}$. Then, a sample of $5 \mathrm{~mL}$ venous blood was drawn from all of the patients and analyzed freshly. The laboratory methods for testing the mentioned outcomes were explained in a previously published paper [34]. Also, patients' weight (without shoes, minimum clothing) was assessed using a calibrated digital scale $\left(\mathrm{Omron}^{\circledR}\right)$.

\section{Data Analysis}

The sample size was calculated based on a 2 means comparison formula, considering the type 1 error of 0.05 and the power of $80 \%$. Regarding the estimated postintervention mean of FBG in the intervention and control groups (148 \pm 12 and $156 \pm 14$, respectively) the required sample was about 30 patients in each group of the trial. Finally, the sample size was set to be 66 patients, by estimating a probable $10 \%$ dropout [35].

Data were presented as means \pm SD or frequency (percent) for quantitative and qualitative variables, respectively. The normal distribution of data was evaluated using the Kolmogorov-Smirnov test. The between-group analyses for both baseline and post-intervention comparison of each outcome measure were later carried out using the independent $t$ test. The between-group comparisons of the mean differences were made using the Mann-Whitney U test, too. The findings were analyzed using SPSS software (SPSS Inc., released 2009; PASW Statistics for Windows, version 18.0; Chicago, SPSS Inc.). In this study, $p<0.05$ was considered as the statistically significant level.

\section{Results}

A total of 33 patients were assigned to the intervention group, 30 of whom completed the study. Moreover, 32 patients were enrolled in the control group, of whom 2 were lost to follow-up. Figure 1 is the summary of the study flow, from screening of participants to assignment, follow-up, and analysis.

Table 1 shows the baseline (i.e., before the intervention) demographic and clinical characteristics of the patients in the 2 groups of the trial. The differences between the 2 groups were not significant in terms of all studied variables.

After the 8-week period of the intervention, the mean value of FBG of the intervention group was $135.83 \pm$ 35.92. It was significantly lower than $(p=0.02)$ this value for the placebo group $(158.84 \pm 39.04)$. Also, the betweengroup comparison of post-intervention $\mathrm{HbA}_{1 \mathrm{c}}$ values of the intervention and placebo groups $(6.94 \pm 0.77$ and 7.53 \pm 0.98 , respectively) revealed a significant difference $(p=$ $0.01)$. However, there were no significant between-group differences regarding postintervention values of TG and cholesterol (Table 2).

An additional analysis regarding the mean differences of the baseline and post-intervention values was done. As 


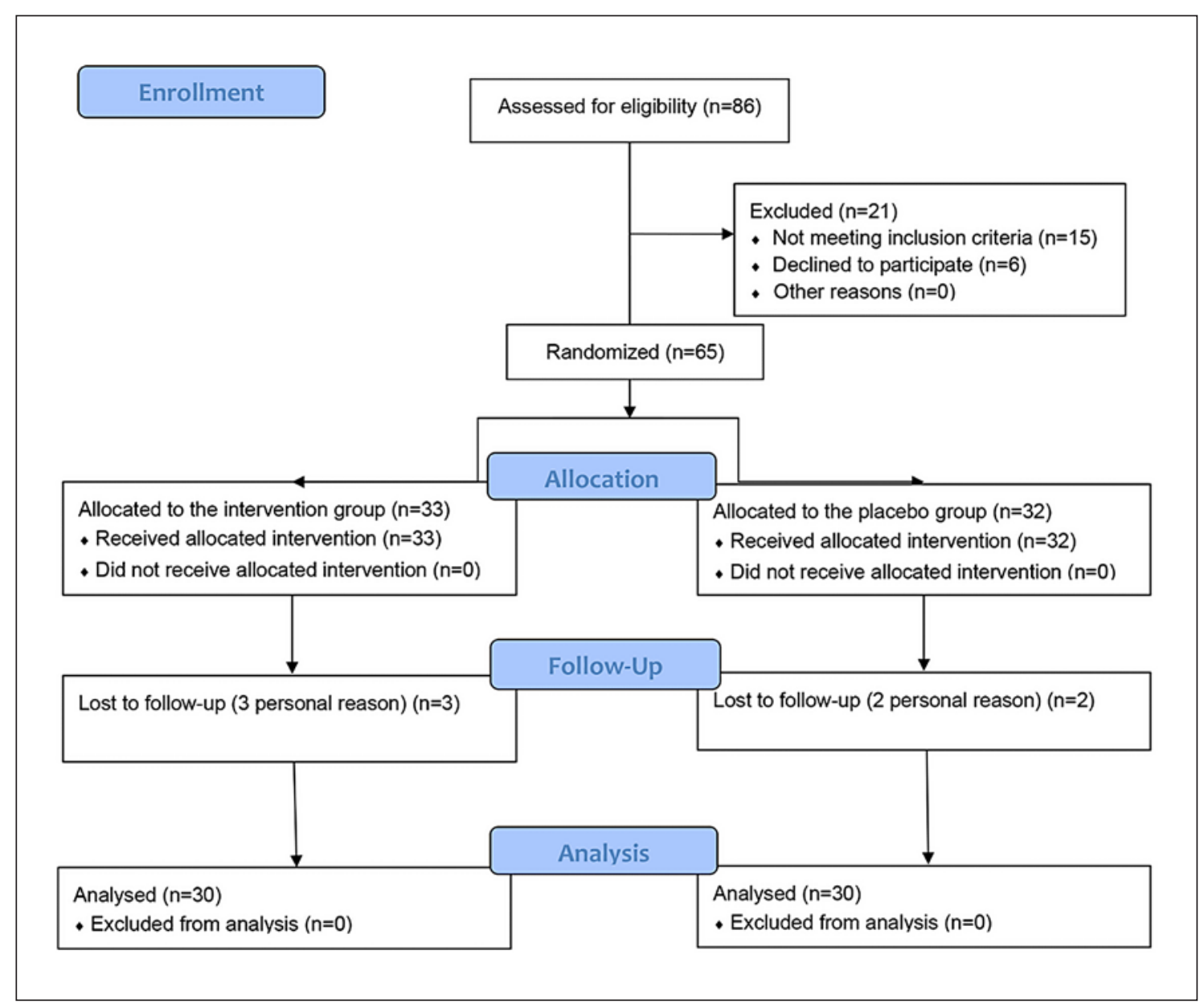

Fig. 1. Summary of the study flow, from screening of participants to assignment, follow-up, and analysis.

shown in Table 2, there were significant between-group differences for all of the assessed outcome measures (Table 2). The assessment of patients' adherence showed that it was $>75 \%$.

\section{Safety}

There were no reports on adverse events (neither major nor minor) in both groups. Only, a few people complained about the tastelessness of the teabags: 3 persons in the PSP group and 4 in the HWPEG group.

\section{Discussion}

This randomized double-blind placebo-controlled clinical trial aimed to investigate the effect of $10 \mathrm{~g}$ PSP ( $5 \mathrm{~g}$, twice daily) for a period of 8 weeks on FBG, $\mathrm{HbA}_{1 \mathrm{c}}$, TG, and cholesterol of patients with T2DM. According to the outcome measures analyzed, it seems that PSP could improve FBG and $\mathrm{HbA}_{1 \mathrm{c}}$ significantly compared to placebo.
Table 1. The baseline characteristics of patients in both groups of intervention (i.e., PSP) and placebo (i.e., HWPEG)

\begin{tabular}{lccc}
\hline Variables & $\begin{array}{c}\text { Intervention } \\
(n=30)\end{array}$ & $\begin{array}{l}\text { Placebo } \\
(n=30)\end{array}$ & $\begin{array}{l}p \\
\text { value }\end{array}$ \\
\hline Gender, $n(\%)$ & & & 0.07 \\
$\quad$ Female & & & \\
$\quad$ Male & $10(33.3)$ & $18(60)$ & \\
Age, years & $20(66.6)$ & $12(40)$ & \\
Weight, kg & $62.54 \pm 6.18$ & $61.67 \pm 4.82$ & 0.23 \\
Duration of disease, year & $74.72 \pm 7.98$ & $73.55 \pm 6.99$ & 0.61 \\
Syst. BP & $5.54 \pm 2.61$ & $5.85 \pm 2.43$ & 0.51 \\
Diast. BP & $125.72 \pm 8$ & $129.19 \pm 7.79$ & 0.47 \\
FBG, mg/dL & $16.07 \pm 6.33$ & $76.58 \pm 5.93$ & 0.76 \\
HbA ${ }_{1 \mathrm{c}}, \mathrm{mg} / \mathrm{dL}$ & $7.97 \pm 8.99$ & $149.48 \pm 22.03$ & 0.49 \\
TG, mg/dL & $163.28 \pm 73.62$ & $149.35 \pm 73.66$ & 0.46 \\
Cholesterol, mg/dL & $168.45 \pm 39.29$ & $158.77 \pm 37.35$ & 0.33 \\
\hline
\end{tabular}

PSP, pomegranate seed powder; HWPEG, high-molecular weight polyethylene glycol; syst. BP, systolic blood pressure; diast. $\mathrm{BP}$, diastolic blood pressure; FBG, fasting blood glucose; $\mathrm{HbA}_{1 \mathrm{c}}$, glycated hemoglobin; TG, triglyceride. 
Table 2. Comparison of the postintervention and mean difference values between the 2 groups of the study

\begin{tabular}{|c|c|c|c|c|c|c|}
\hline Variables & Groups & Before & After & $p$ value $^{\mathrm{a}}$ & Mean difference & $p$ value \\
\hline FBG, $\mathrm{mg} / \mathrm{dL}$ & $\begin{array}{l}\text { Intervention }(n=30) \\
\text { Placebo }(n=30)\end{array}$ & $\begin{array}{l}141.97 \pm 8.99 \\
149.48 \pm 22.03\end{array}$ & $\begin{array}{l}135.83 \pm 35.92 \\
158.84 \pm 39.04\end{array}$ & 0.02 & $\begin{array}{r}6.13 \pm 30.51 \\
-9.35 \pm 44.99\end{array}$ & 0.01 \\
\hline $\mathrm{HbA}_{1 \mathrm{c}}, \mathrm{mg} / \mathrm{dL}$ & $\begin{array}{l}\text { Intervention }(n=30) \\
\text { Placebo }(n=30)\end{array}$ & $\begin{array}{l}7.27 \pm 0.84 \\
7.17 \pm 0.94\end{array}$ & $\begin{array}{l}6.94 \pm 0.77 \\
7.53 \pm 0.98\end{array}$ & 0.01 & $\begin{array}{r}0.32 \pm 0.33 \\
-0.42 \pm 1.09\end{array}$ & 0.001 \\
\hline $\mathrm{TG}, \mathrm{mg} / \mathrm{dL}$ & $\begin{array}{l}\text { Intervention }(n=30) \\
\text { Placebo }(n=30)\end{array}$ & $\begin{array}{l}163.28 \pm 73.62 \\
149.35 \pm 73.66\end{array}$ & $\begin{array}{l}151.24 \pm 67.94 \\
172.78 \pm 78.45\end{array}$ & 0.26 & $\begin{array}{r}12.03 \pm 22.43 \\
-23.51 \pm 64.28\end{array}$ & 0.002 \\
\hline Cholesterol, mg/dL & $\begin{array}{l}\text { Intervention }(n=30) \\
\text { Placebo }(n=30)\end{array}$ & $\begin{array}{l}168.45 \pm 39.29 \\
158.77 \pm 37.35\end{array}$ & $\begin{array}{l}159.62 \pm 33.52 \\
165.42 \pm 34.97\end{array}$ & 0.51 & $\begin{array}{r}8.82 \pm 23.89 \\
-6.64 \pm 48.37\end{array}$ & 0.02 \\
\hline
\end{tabular}

FBG, fasting blood glucose; $\mathrm{HbA}_{1 c}$, glycated hemoglobin; TG, triglyceride. ${ }^{\text {a }}$ Between-group comparison of post-intervention values.

PSP is commonly known as a byproduct of pomegranate processing in food science. However, PSP is increasingly known as a good source of nutrients [36, 37]. PSP has shown its radical scavenging and antioxidant [38-41], antiviral and antifungal [42], and environmental toxic agent removal [43] activity. Additionally, its activity against DNA damage, cancer, and some other disorders has been proved $[44,45]$. PSP possesses different wellknown biologically active compounds, such as polyphenols [46], tocopherols [47, 48], vitamins, minerals, and isoflavones [49]. Moreover, its oil contains $65-80 \%$ conjugated linolenic acids (including punicic acid) which are popular for multiple health purposes [50].

Many studies have been conducted on the effects of different parts of pomegranate on patients with T2DM, especially about blood glucose levels. Also, there are many preclinical studies about the effects of different pomegranate seed products on DM. For example, oral consumption of its methanolic extract (in 2 different doses of 300 and $600 \mathrm{mg} / \mathrm{kg}$ ) significantly decreased diabetic rats' blood glucose, even after $12 \mathrm{~h}$ [51]. Also, the results of another study on diabetic rats showed that the pomegranate seed oil was effective in increasing insulin secretion but did not affect the blood glucose level [52].

Another study by Jelodar et al. [53] (2007) showed antihyperglycemic activity of a diet containing PSP (60 g/ $\mathrm{kg} /$ day) as $13.1 \%$. Also, the findings of a study by Harzallah et al. [54] (2016) revealed insulin-sensitizing and FBG-decreasing effects of a pomegranate seed product. Moreover, they showed its anti-inflammatory effects by decreased levels of interleukin 6 and tumor necrosis factor $\alpha$. Additionally, its improving effects on insulin sensitivity have been shown in CD-1 mice. The latter study showed its activity on increasing levels of leptin and decreased levels of adiponectin, too [55].

Based on previous research, pomegranate seed increased insulin secretion and upregulated and activated the glucose transporter type 4 expression [56]. In addi- tion, it can also increase the peroxisome proliferator-activated receptors $\gamma$ and $\alpha$ response genes [57].

Moreover, there are many studies about the effects of different pomegranate seed products on lipid profile and metabolism [32]. For instance, pomegranate seed supplementation in rats has been shown to have protective effects against methotrexate-induced alterations of total, high-, and low-density lipoprotein cholesterols [58]. As reported by Nekooeian et al. [52], pomegranate seed supplementation in diabetic rats had no significant effects on the serum levels of TG, total, high-, and low-density lipoprotein cholesterols when compared with diabetic controls. However, another research showed that it significantly raised serum total, high-, and low-density lipoprotein cholesterols compared to controls [29], while the other study on hypercholesterolemic rats demonstrated a significant reduction of TG, total, and low-density lipoprotein cholesterols, and lipid peroxidation by its supplementation [59].

Scientific disagreement on the effects of pomegranate seed on lipid profile in human studies is seen, too. Two clinical trials reported its beneficial effect on high-density lipoprotein cholesterol or TG/high-density lipoprotein ratio $[60,61]$, while another one reported a non-significant effect on high-density lipoprotein [35]. Also, TG was reported to be reduced [61] and not reduced by its administration [35]. However, total and low-density lipoprotein cholesterol serum levels seem to be not influenced by its use $[35,61]$.

All in all, it seems that previous researches demonstrated controversial findings about the effect of pomegranate seed on lipid metabolism and profile. It may be due to different sample populations (e.g., diabetics and hyperlipidemics) and dissimilar doses of pomegranate seed and duration of intervention. In addition, different pomegranate seed products from a wide variety of countries may have not the same effective phytochemicals for lipid profile treatment. 
Nevertheless, it seems that more rigorous studies are necessitated for elucidating our scientific mechanistic understanding on PSP efficacy for T2DM. Additionally, it is strongly suggested to test its metabolic effects on patients with T2DM via more clinical trials involving larger sample sizes. Especially, there is a need to assess its efficacy versus active treatments for DM and dyslipidemia (such as oral hypoglycemic agents).

PSP has its own advantages as a potential antidiabetic agent. It is a cheap medicine, regarding its byproduct nature. Also, it is an available natural product. Moreover, no adverse reactions have been reported during its use.

\section{Limitations of the Study}

This study had several limitations. We had not enough resources to standardize the used PSP product. Also, the period of intervention was relatively short. We did do the intervention for an 8-week period (as a relatively acceptable and usual period for clinical trials on DM), followed by re-assessment of outcome measures. Surely, extending this time helps us to achieve more reliable results. Another concern is the small cohort of the patients. Moreover, we had no interim measurement. It could show the trend of outcome measures' change during time. Additionally, we did not measure high- and lowdensity lipoprotein cholesterol levels for the evaluation of PSP effects on lipid profiles. Physical activity and dietary intake assessment of patients are advised to be done in future studies. It can make more reliable judgment on the homogeneity of participants in different groups. Finally, there are some problems on generalizability of the findings. We did not include patients under insulin therapy. Also, patients with DM complications were ruled out. In other words, the included patients had more benign T2DM. Therefore, there are some difficulties on generalization of the results for patients with T2DM. Future studies about PSP and DM are recommended to be done as effectiveness trials to assess its effect in a community-based or real-world setting. In addition, development and assessment of patient-friendly dosage forms (e.g., tablet or capsule and sustained-release preparations) are recommended.

\section{Conclusion}

According to the findings of this randomized doubleblind controlled clinical trial, the use of $5 \mathrm{~g}$ PSP twice daily has beneficial effects on $\mathrm{FBG}$ and $\mathrm{HbA}_{1 \mathrm{c}}$ of patients with T2DM when compared to placebo. However, its effect on TG and cholesterol was equivocal. It seems that PSP can be recommended as a complementary treatment for T2DM patients who are on oral hypoglycemic agents. However, further studies with longer duration and larger sample size are recommended to approve the use of PSP in clinical practice.

\section{Statement of Ethics}

The study design was in accordance with the Declaration of Helsinki's principles (1989 revision) and national ethics guidelines on human studies. Also, it was approved by the Local Medical Ethics Committee of Yazd Shahid Sadoughi University of Medical Sciences (approval ID: IR.SSU.REC.1395.106). Moreover, the trial protocol was registered at the public trial registry of Iran (registration No.: IRCT20170125032171N2). Written informed consent forms were signed before the patients' enrollment, as well.

\section{Conflict of Interest Statement}

The authors declare that there is no conflict of interest.

\section{Funding Sources}

This study was financially supported by Yazd Shahid Sadoughi University of Medical Sciences. The funding organization had no role in study design, data collection and analysis, interpretation of data, and manuscript preparation.

\section{Author Contributions}

M.S.H.: conception and design, acquisition of data, and writing of the original draft; N.N. and M.E.: conception and design, and writing of review and editing; H.T., A.D., M.H.R., and S.J.A.: acquisition of data, and writing of review and editing; M.H.H.: analysis and interpretation of data, and writing of the original draft. All the authors read and approved the final version of the paper.

\section{References}

1 American Diabetes Association. Diagnosis and classification of diabetes mellitus. Diabetes Care. 2014 Jan;37(Suppl 1):S81-90.

2 Liu X, Liu W, Ding C, Zhao Y, Chen X, Khatoon S, et al.Antidiabetic Effects of ArginylFructosyl-Glucose, a Nonsaponin Fraction from Ginseng Processing in StreptozotocinInduced Type 2 Diabetic Mice through Regulating the PI3K/AKT/GSK-3 $\beta$ and Bcl-2/Bax Signaling Pathways. Evid Based Complement Alternat Med. 2020 Jul 2;2020:3707904.
3 Oguntibeju OO. Type 2 diabetes mellitus, oxidative stress and inflammation: examining the links. Int J Physiol Pathophysiol Pharmacol. 2019 Jun;11(3):45-63.

4 Atlas D. International Diabetes Federation. IDF Diabetes Atlas. 9th ed. Brussels, Belgium: International Diabetes Federation; 2019.

5 Osati S, Homayounfar R, Hajifaraji M. Metabolic effects of vitamin D supplementation in vitamin $\mathrm{D}$ deficient patients (a double-blind clinical trial). Diabetes Metab Syndr. 2016 Apr-Jun;10(2 Suppl 1):S7-10. 
6 Forouzanfar MH, Afshin A, Alexander LT, Anderson HR, Bhutta ZA, Biryukov S, et al.; GBD 2015 Risk Factors Collaborators. Global, regional, and national comparative risk assessment of 79 behavioural, environmental and occupational, and metabolic risks or clusters of risks, 1990-2015: a systematic analysis for the Global Burden of Disease Study 2015. Lancet. 2016 Oct;388(10053):1659-724

7 Holman N, Young B, Gadsby R. Current prevalence of Type 1 and Type 2 diabetes in adults and children in the UK. Diabet Med. 2015 Sep;32(9):1119-20.

8 Zheng Y, Ley SH, Hu FB. Global aetiology and epidemiology of type 2 diabetes mellitus and its complications. Nat Rev Endocrinol. 2018 Feb;14(2):88-98.

9 Rodríguez-Gutiérrez R, Montori VM. Glycemic Control for Patients With Type 2 Diabetes Mellitus: Our Evolving Faith in the Face of Evidence. Circ Cardiovasc Qual Outcomes. 2016 Sep;9(5):504-12.

10 Wanchai A, Phrompayak D. Use of complementary and alternative medicine among Thai patients with type 2 diabetes mellitus. J Integr Med. 2016 Jul;14(4):297-305.

11 Hashempur MH, Mosavat SH, Heydari M, Shams M. Medicinal plants' use among patients with dyslipidemia: an Iranian cross-sectional survey. J Complement Integr Med. 2018 Nov;16(3):/j/jcim.2019.16.issue-3/jcim2018-0101/jcim-2018-0101.xml.

12 Shakeri A, Hashempur MH, Mojibian M, Aliasl F, Bioos S, Nejatbakhsh F. A comparative study of ranitidine and quince (Cydonia oblonga mill) sauce on gastroesophageal reflux disease (GERD) in pregnancy: a randomised, open-label, active-controlled clinical trial. J Obstet Gynaecol. 2018 Oct;38(7): 899-905.

13 Khiveh A, Hashempur MH, Shakiba M, Lotfi $\mathrm{MH}$, Shakeri A, Kazemeini S, et al. Effects of rhubarb (Rheum ribes L.) syrup on dysenteric diarrhea in children: a randomized, doubleblind, placebo-controlled trial. J Integr Med. 2017 Sep;15(5)e39744365-72.

14 Akrami R, Hashempur MH, Tavakoli A, Nimrouzi M, Sayadi M, Roodaki M, et al. Effects of Fumaria parviflora L on uremic pruritus in hemodialysis patients: a randomized, double-blind, placebo-controlled trial. Jundishapur J Nat Pharm Prod. 2016;12(3) e39744e39744.

15 Seyed Hashemi M, Hashempur MH, Lotfi MH, Hemat H, Mousavi Z, Emtiazy M, et al. The efficacy of asafoetida (Ferula assa-foetida oleo-gum resin) versus chlorhexidine gluconate mouthwash on dental plaque and gingivitis: A randomized double-blind controlled trial. Eur J Integr Med. 2019;29:100929y

16 Hashempur MH, Khademi F, Rahmanifard M, Zarshenas MM. An evidence-based study on medicinal plants for hemorrhoids in Medieval Persia. J Evid Based Complementary Altern Med. 2017 Oct;22(4):969-81.

17 Shaygannia E, Bahmani M, Zamanzad B, Rafieian-Kopaei M. A Review Study on Punica granatum L. J Evid Based Complementary Altern Med. 2016 Jul;21(3):221-7.
18 Kamali M, Tavakoli H, Khodadoost M, Daghaghzadeh H, Kamalinejad M, Gachkar L, et al. Efficacy of the Punica granatum peels aqueous extract for symptom management in ulcerative colitis patients. A randomized, placebo-controlled, clinical trial. Complement Ther Clin Pract. 2015 Aug;21(3):141-6.

19 Hosseini B, Saedisomeolia A, Wood LG, Yaseri M, Tavasoli S. Effects of pomegranate extract supplementation on inflammation in overweight and obese individuals: A randomized controlled clinical trial. Complement Ther Clin Pract. 2016 Feb;22:44-50.

20 Stowe CB. The effects of pomegranate juice consumption on blood pressure and cardiovascular health. Complement Ther Clin Pract. 2011 May;17(2):113-5.

21 Wu S, Tian L. Diverse Phytochemicals and Bioactivities in the Ancient Fruit and Modern Functional Food Pomegranate (Punica granatum). Molecules. 2017 Sep;22(10):E1606.

22 Beigi Boroujeni M, Shahrokhi SS, Birjandi M, Abbaszadeh A, Beyranvand F, Hamoleh S, et al. Effects of pomegranate peel extract on histopathology, testosterone levels and sperm of testicular torsion-detorsion induced in adult Wistar rats. J Complement Integr Med. 2017 Jul; 14(4):/j/jcim.2017.14.issue-4/jcim-20170009/jcim-2017-0009.xml.

23 Mollazadeh H, Sadeghnia HR, Hoseini A, Farzadnia M, Boroushaki MT. Effects of pomegranate seed oil on oxidative stress markers, serum biochemical parameters and pathological findings in kidney and heart of streptozotocin-induced diabetic rats. Ren Fail. 2016 Sep;38(8):1256-66.

24 Danesi F, Ferguson LR. Could Pomegranate Juice Help in the Control of Inflammatory Diseases? Nutrients. 2017 Aug;9(9):E958.

25 Panth N, Manandhar B, Paudel KR. Anticancer Activity of Punica granatum (Pomegranate): A Review. Phytother Res. 2017 Apr; 31(4):568-78.

26 Zhao B, Liu H, Wang J, Liu P, Tan X, Ren B, et al. Lycopene supplementation attenuates oxidative stress, neuroinflammation, and cognitive impairment in aged CD-1 mice. J Agric Food Chem. 2018 Mar;66(12):3127-36.

27 Asgary S, Keshvari M, Sahebkar A, Sarrafzadegan N. Pomegranate Consumption and Blood Pressure: A Review. Curr Pharm Des. 2017;23(7):1042-50

28 Hou C, Zhang W, Li J, Du L, Lv O, Zhao S, et al. Beneficial Effects of Pomegranate on Lipid Metabolism in Metabolic Disorders. Mol Nutr Food Res. 2019 Aug;63(16):e1800773.

29 Taheri Rouhi SZ, Sarker MM, Rahmat A, Alkahtani SA, Othman F. The effect of pomegranate fresh juice versus pomegranate seed powder on metabolic indices, lipid profile, inflammatory biomarkers, and the histopathology of pancreatic islets of Langerhans in streptozotocin-nicotinamide induced type 2 diabetic Sprague-Dawley rats. BMC Complement Altern Med. 2017 Mar;17(1):156.

$30 \mathrm{Xu} \mathrm{KZ,} \mathrm{Zhu} \mathrm{C,} \mathrm{Kim} \mathrm{MS,} \mathrm{Yamahara} \mathrm{J,} \mathrm{Li} \mathrm{Y.}$ Pomegranate flower ameliorates fatty liver in an animal model of type 2 diabetes and obesity. J Ethnopharmacol. 2009 Jun;123(2):2807.
31 Li Y, Wen S, Kota BP, Peng G, Li GQ, Yamahara J, et al. Punica granatum flower extract, a potent alpha-glucosidase inhibitor, improves postprandial hyperglycemia in Zucker diabetic fatty rats. J Ethnopharmacol. 2005 Jun;99(2):239-44.

32 Banihani S, Swedan S, Alguraan Z. Pomegranate and type 2 diabetes. Nutr Res. 2013 May;33(5):341-8.

33 American Diabetes Association. Standards of Medical Care in Diabetes-2016 Abridged for Primary Care Providers. Clin Diabetes. 2016 Jan;34(1):3-21.

34 Zare R, Nadjarzadeh A, Zarshenas MM, Shams M, Heydari M. Efficacy of cinnamon in patients with type II diabetes mellitus: A randomized controlled clinical trial. Clin Nutr. 2019 Apr;38(2):549-56.

35 Faghihimani Z, Mirmiran P, Sohrab G, Iraj B, Faghihimani E. Effects of pomegranate seed oil on metabolic state of patients with Type 2 diabetes mellitus. Int J Prev Med. 2016 Nov; $7(1): 124$.

36 Jing P, Ye T, Shi H, Sheng Y, Slavin M, Gao B, et al. Antioxidant properties and phytochemical composition of China-grown pomegranate seeds. Food Chem. 2012 Jun;132(3):145764.

37 Bourekoua H, Różyło R, Gawlik-Dziki U, Benatallah L, Zidoune MN, Dziki D. Pomegranate seed powder as a functional component of gluten-free bread (Physical, sensorial and antioxidant evaluation). Int J Food Sci Technol. 2018;53(8):1906-13.

38 Dib A, Kasprzak K, Wójtowicz A, Benatallah L, Waksmundzka-Hajnos M, Zidoune MN, et al. The effect of pomegranate seed powder addition on radical scavenging activity determined by TLC-DPPH test and selected properties of gluten-free pasta. J Liq Chromatogr Relat Technol. 2018;41(6):364-72.

39 Qin YY, Zhang ZH, Li L, Xiong W, Shi JY, Zhao TR, et al. Antioxidant effect of pomegranate rind powder extract, pomegranate juice, and pomegranate seed powder extract as antioxidants in raw ground pork meat. Food Sci Biotechnol. 2013;22(4):1063-9.

40 Saeidi Z, Nasehi B, Jooyandeh H. Optimization of gluten-free cake formulation enriched with pomegranate seed powder and transglutaminase enzyme. J Food Sci Technol. 2018 Aug;55(8):3110-8.

41 Tehranifar A, Zarei M, Nemati Z, Esfandiyari $B$, Vazifeshenas MR. Investigation of physicochemical properties and antioxidant activity of twenty Iranian pomegranate (Punica granatum L.) cultivars. Sci Hortic (Amsterdam). 2010;126(2):180-5.

42 Yefsah-Idres A, Benazzoug Y, Otman A, Latour A, Middendorp S, Janel N. Hepatoprotective effects of lycopene on liver enzymes involved in methionine and xenobiotic metabolism in hyperhomocysteinemic rats. Food Funct. 2016 Jun;7(6):2862-9.

43 Ghaneian MT, Jamshidi B, Amrollahi M, Dehvari M, Taghavi M. Application of biosorption process by pomegranate seed powder in the removal of hexavalent chromium from aqueous environment. Koomesh. 2014;15(2): 206-11. 
44 Guo S, Deng Q, Xiao J, Xie B, Sun Z. Evaluation of antioxidant activity and preventing DNA damage effect of pomegranate extracts by chemiluminescence method. J Agric Food Chem. 2007 Apr;55(8):3134-40.

45 Lansky EP, Newman RA. Punica granatum (pomegranate) and its potential for prevention and treatment of inflammation and cancer. J Ethnopharmacol. 2007 Jan;109(2):177206.

46 Balasundram N, Sundram K, Samman S. Phenolic compounds in plants and agri-industrial by-products: antioxidant activity, occurrence, and potential uses. Food Chem. 2006; 99(1):191-203.

47 Elfalleh W, Tlili N, Nasri N, Yahia Y, Hannachi $\mathrm{H}$, Chaira $\mathrm{N}$, et al. Antioxidant capacities of phenolic compounds and tocopherols from Tunisian pomegranate (Punica granatum) fruits. J Food Sci. 2011 Jun-Jul;76(5):C70713.

48 Caligiani A, Bonzanini F, Palla G, Cirlini M, Bruni R. Characterization of a potential nutraceutical ingredient: pomegranate (Punica granatum L.) seed oil unsaponifiable fraction. Plant Foods Hum Nutr. 2010 Sep;65(3):27783.

49 Aruna P, Venkataramanamma D, Singh AK, Singh R. Health benefits of punicic acid: a review. Compr Rev Food Sci Food Saf. 2016; 15(1):16-27.
50 Abbasi H, Rezaei K, Rashidi L. Extraction of essential oils from the seeds of pomegranate using organic solvents and supercritical CO2. J Am Oil Chem Soc. 2008;85(1):83-9.

51 Das AK, Mandal SC, Banerjee SK, Sinha S, Saha BP, Pal M. Studies on the hypoglycaemic activity of Punica granatum seed in streptozotocin induced diabetic rats. Phytother Res. 2001 Nov;15(7):628-9.

52 Nekooeian AA, Eftekhari MH, Adibi S, Rajaeifard A. Effects of pomegranate seed oil on insulin release in rats with type 2 diabetes. Iran J Med Sci. 2014 Mar;39(2):130-5.

53 Jelodar G, Mohsen M, Shahram S. Effect of walnut leaf, coriander and pomegranate on blood glucose and histopathology of pancreas of alloxan induced diabetic rats. Afr J Tradit Complement Altern Med. 2007 Feb;4(3):299305.

54 Harzallah A, Hammami M, Kępczyńska MA, Hislop DC, Arch JR, Cawthorne MA, et al. Comparison of potential preventive effects of pomegranate flower, peel and seed oil on insulin resistance and inflammation in high-fat and high-sucrose diet-induced obesity mice model. Arch Physiol Biochem. 2016;122(2): 75-87.

55 McFarlin BK, Strohacker KA, Kueht ML. Pomegranate seed oil consumption during a period of high-fat feeding reduces weight gain and reduces type 2 diabetes risk in CD-1 mice. Br J Nutr. 2009 Jul;102(1):54-9.
56 Anusree SS, Nisha VM, Priyanka A, Raghu $\mathrm{KG}$. Insulin resistance by TNF- $\alpha$ is associated with mitochondrial dysfunction in 3T3-L1 adipocytes and is ameliorated by punicic acid, a PPAR $\gamma$ agonist. Mol Cell Endocrinol. 2015 Sep;413:120-8.

57 Khajebishak Y, Payahoo L, Alivand M, Alipour B. Punicic acid: A potential compound of pomegranate seed oil in Type 2 diabetes mellitus management. J Cell Physiol. 2019 Mar;234(3):2112-20.

58 Doostan F, Vafafar R, Zakeri-Milani P, Pouri A, Amini Afshar R, Mesgari Abbasi M. Effects of Pomegranate (Punica Granatum L.) Seed and Peel Methanolic Extracts on Oxidative Stress and Lipid Profile Changes Induced by Methotrexate in Rats. Adv Pharm Bull. 2017 Jun;7(2):269-74

59 Elbandy M, Ashoush I. Phytochemicals in pomegranate seeds and their effect as hypolipidemic agent in hypercholesterolemic rats. World J Dairy Food Sci. 2012;7(1):85-92.

60 Shahidi F, Moonikh K. Effects of pomegranate seed oil followed by resistance exercise on insulin resistance and lipid profile in non-athletic men. Feyz Journal of Kashan University of Medical Sciences. 2017;21(3):224-31.

61 Mirmiran P, Fazeli MR, Asghari G, Shafiee A, Azizi F. Effect of pomegranate seed oil on hyperlipidaemic subjects: a double-blind placebo-controlled clinical trial. Br J Nutr. 2010 Aug;104(3):402-6. 